\title{
Circulation of Coxsackievirus A6 in hand-foot-mouth disease in Guangzhou, 2010-2012
}

\author{
Biao Di ${ }^{\dagger}$, Ying Zhang ${ }^{\dagger}$, Huaping Xie ${ }^{\dagger}$, Xiaoquan $\mathrm{Li}^{\dagger}$, Chun Chen, Peng Ding, Peng He, Dahu Wang, Jinmei Geng, \\ Lei Luo, Zhijun Bai, Zhicong Yang and Ming Wang*
}

\begin{abstract}
Background: Hand, foot and mouth disease (HFMD) is usually caused by Enterovirus 71(EV71), and Coxsackievirus A16 (CV-A16) in Guangzhou, the biggest city of South China. However, Coxsackievirus A6 (CV-A6) were observed increased dramatically from 2010-2012.

Methods: In order to understand and to describe the epidemiologic and genetic characteristics of CV-A6, specimens of 5482 suspected HFMD cases were collected and examined by real-time fluorescence PCR. All samples positive for enteroviruses were analyzed by descriptive statistics. Phylogenetic analysis of CV-A6 based on the VP1 sequences was performed to investigate molecular and evolutionary characteristics.

Results: Coxsackievirus A6 increased dramatically from 9.04\% in 2010 to 23.21\% in 2012 and became one of the main causative agents of HFMD in Guangzhou. CV-A6 attack rates were highest in one to two year olds (33.14\%). Typical clinic symptoms of CV-A6 HFMD include fever (589/720, 81.81\%), maculopopular rash and vesicular exanthema around the perioral area (408/720,56.66\%), intraoral (545/720, 75.69\%), the buttock (395/720, 54.86\%), the trunk (244/720,33.89\%), the knee (188/720, 26.11\%), and the dorsal aspects of hands (437/720, 60.69\%). Phylogenetic analysis showed the CV-A6 isolates in this study belonged to Cluster A1 and were similar to those found in Shanghai in 2011 and 2012 (JX495148, KC414735), Shenzhen in 2011 (JX473394), Japan in 2011 (AB649243, AB649246), France in 2010(HE572928), Thailand in 2012(JX556564) and Israel in 2012 and 2013(.KF991010, KF991012).
\end{abstract}

Keywords: Hand, Foot and mouth disease, Coxsackievirus A6, Epidemiologic feature, Molecular analysis

\section{Background}

Hand, foot and mouth disease (HFMD) is a common epidemic causing childhood infection caused by enteroviruses. The causative enteroviruses include Coxsackievirus $\mathrm{A}(2-8,10,12,14,16)$, Coxsackievirus $\mathrm{B}(2,5)$ and enterovirus (EV) 71 . EV 71 and CV-A16 are the most common. HFMD primarily afflicts infants and children younger than 5 years. Primary symptoms are fever, rash or herpes of the hand, feet and oral cavity. HFMD was first described in 1957 by Seddon in New Zealand. In 1958, CV-A16 was isolated by Robinson et al. in Canada [1]. In 1959, the disease was formally named HFMD. EV71 was isolated in 1969 and determined to be a HFMD causing agent in 1972 [2]. Since then, numerous EV71 and CVA16 caused HFMD outbreaks have been reported [3].

\footnotetext{
* Correspondence: wangming@gzcdc.org.cn

${ }^{\dagger}$ Equal contributors

Guangzhou Center for Disease Control and Prevention, NO.1, Qide Road, Baiyun District, Guangzhou, Guangdong, 510440, China
}

In China the first case of HFMD was reported in Shanghai in 1982, followed by reports in more than ten provinces and cities, including Beijing, Hebei, Tianjin, Shandong and Guangdong. These reports included several outbreaks of epidemic proportions [4-6]. The etiology of HFMD in China is similar to that described in many other countries of Asia and the world. The major HFMD causing pathogen was CV-A16 in the 1980s and EV71 in the 1990s but caseloads remained low until 2008 when a nationwide epidemic occurred. Subsequently HFMD was named a $\mathrm{C}$-class infectious disease by the national government $[7,8]$. In Guangzhou, HFMD associated morbidity is higher than the national average [9]. In addition to high rates of EV71 and CV-A16 infections, $\mathrm{CV}-\mathrm{A} 6$ has also emerged as a major disease causing strain based on our surveillance. In order to fully understand the epidemic and to develop appropriate control strategies, this paper analyzed the molecular epidemiology and disease characteristics of HFMD 
caused by CV-A6 in Guangzhou over the period from 2010 to 2012.

\section{Results and discussion}

From January 2010 to December 2012, a total of 5482 suspected HFMD cases were identified, 4111 (75\%) of which were positive by the pan-EV test (pan EV fluorescent kit from Guangzhou Huayin Medical Technology Inc.). Of the 4111 pan-EV positive cases, the most frequently presented serotypes were EV71 (1443, 35.10\%), CV-A16 (1261, 30.67\%), and CV-A6 (720, 17.51\%) and untyped enteroviruses (604, 14.69\%). EV71 and CV-A16 co-infection cases were 83 (2.02\%).

\section{Distribution of CV-A6 by year}

HFMD cases were reported in every month except for February, 2010 and January and March, 2011. The proportion of CV-A6 infections increased each year from $9.04 \%(106 / 1173)$ in 2010 to $17.58 \%(212 / 1206)$ in 2011 and $23.21 \%(402 / 1732)$ in 2012 . CV-A6 was the main cause of autumn peaks in 2010 and 2012 respectively, while distributed evenly from July to September and reappeared in November, 2011. The proportion of CV-A6 among the total enterovirus types attained peak in November, 2012. Compared to EV71 and CV-A16, the prevalent season for $\mathrm{CV}-\mathrm{A} 6$ was warm season in 2010 and 2011, while was cool season in 2012 (Figure 1).

The predominant autumn pathogen switched from CV-A6 in 2010 to CV-A16 in 2011, and switched to CVA6 again in 2012. The proportion of HFMD cases positive for enterovirus varied significantly between years, as did the proportion of each serotype. The enterovirus positive rate was $94.73 \%(1173 / 1243)$ in $2010,58.85 \%$ (1206/2049) in 2011 and $79.01 \%$ in 2012 (1732/2192). EV71 and CV-A16 remained the most frequent serotypes in each year. Conversely the proportion of other EVs decreased each year from $24.72 \%$ (290/1173) in 2010 to $15.26 \%(184 / 1206)$ in 2011 and to $7.51 \%$ (130/ 1732) in 2012. EV71 and CV-A16 co-infection increased from $0.91 \%$ to $3.06 \%(51 / 1732)$ in 2012 (Figure 2).
Distribution of CV-A6 infection and disease characteristics Of the total 4111 pan-EV positive HFMD cases, 3547 $(86.28 \%)$ patients were recorded with age and gender, ranging from 1 month to 30 years (median: 2 years) and $1827(52.94 \%, 1827 / 3451)$ were male.

Among the patients positive for EVs, 77.54\% were aged between one and four. Significant differences in attack rates for each EV serotype were observed for each age group. CV-A6 (173/522, 33.14\%) was most common in children aged one to two, however EV71 (376/1281, 29.35\%) and CV-A16 (376/1086, 34.62\%) were most common in children aged three to four $\left(\chi^{2}=118.818\right.$, $P<0.05)$. The ratio of males to females positive for CV-A6 was 1.72:1 and no significant difference for each EV serotype $\left(\chi^{2}=0.708, P>0.05\right.$, Table 1$)$.

Typical Clinical signs and symptoms of HFMD caused by CV-A6 were fever (560/720, 77.78\%), vesicular eruptions around the perioral area (408/720, 56.66\%), intraoral (545/720, 75.69\%), the buttock (395/720, $54.86 \%)$, the trunk (244/720, 33.89\%), the knee $(188 / 720$, $26.11 \%)$, and the dorsal aspects of hands (437/720, $60.69 \%)$ in addition to the usual manifestation of skin eruptions on the hands, feet, and mouth. (Figure 3) According to our follow up survey by phone, some recovered patients had nail loss 1 month after initial symptoms. Most cases of HFMD were self-limited and only 8 of 31 severe cases were CV-A6 infection which suffered from meningitis. None CV-A6 infected patient died during 3 years. Other 23 severe cases were EV71 positive.

\section{Phylogenetic analysis}

The 344bp VP1 region (2561nt-2904nt, responding to AY421764) were sequenced from CV-A6 isolates and 72 representative isolates were selected to perform phylogenetic analysis. Among those isolates, 43 were selected to represent 22 clustered cases and outbreaks in different locations and times, as well as 29 were selected from sporadic cases, including 8 severe infections (Additional file 1: Table S2). The sequences were submitted to GenBank

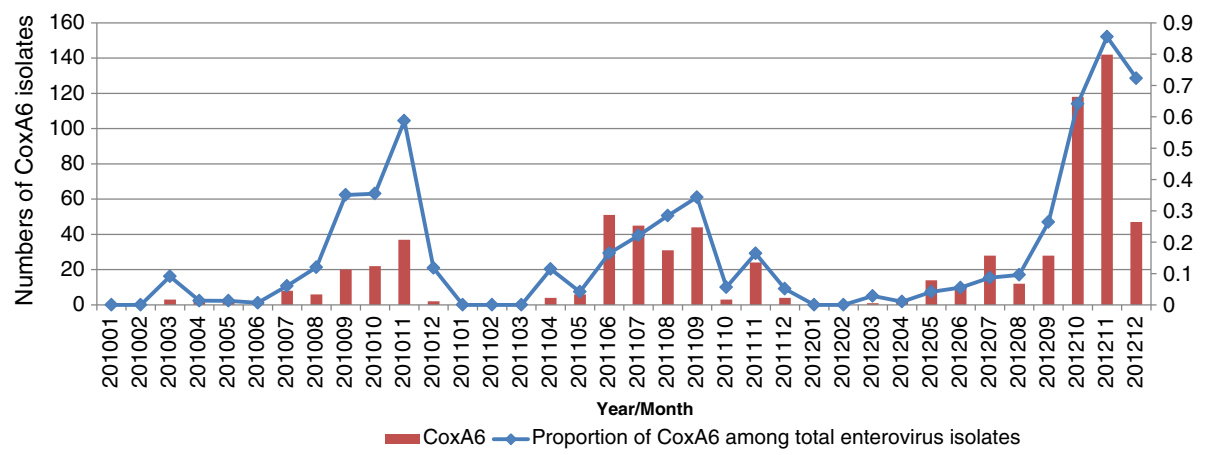

Figure 1 Monthly distribution of 720 CV-A6 isolates from 2010 to 2012 in Guangzhou, China. 


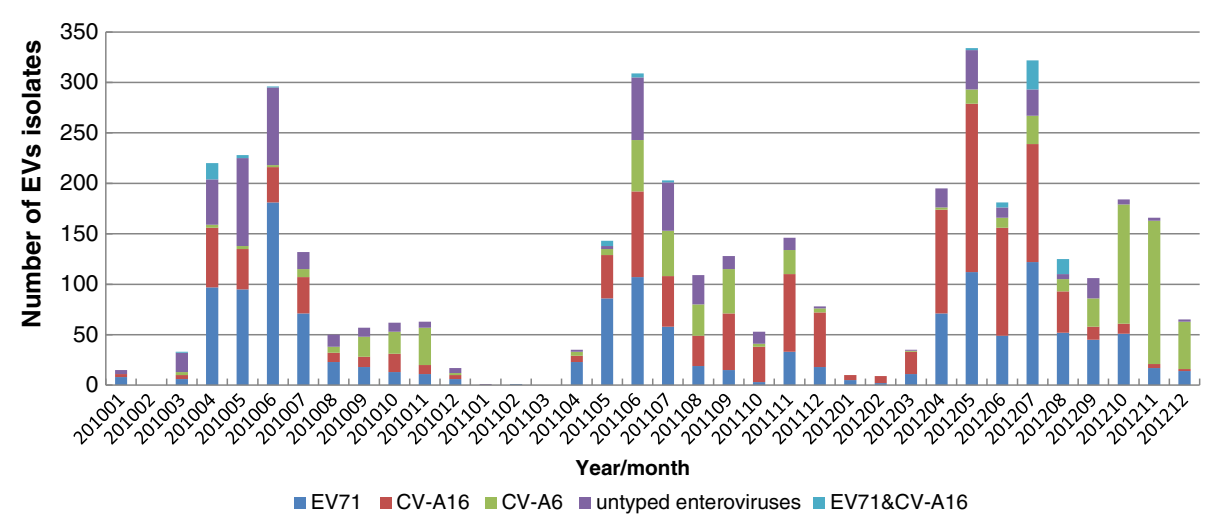

Figure 2 Distribution of EVS types in hand-foot-mouth diseases patients during 2010 to 2012, Guangzhou.

under accession numbers (KF535162-KF535186, KF639916KF639926, KM262854-KM262889). The sequence of 38 additional isolates, representing the full CV-A6 geographic and time diversity and previously reported isolates from China and the world, were downloaded from GenBank and were subjected to phylogenetic analysis together with our isolates.

Across all three years the nucleic acid and deduced amino acid homology of 72 CV-A6 subtypes was $89.25 \%$ 100\% and $92.92 \% \sim 100 \%$, respectively. The nucleic acid sequences of 44 isolates from 2010 and 2011 had higher homology (92.31 100\% identity), whereas the nucleotide identities between 2012 and 2010, 2012 and 2011 isolates were $89.91 \% \sim 99.4 \%$ and $89.25 \% \sim 100 \%$, respectively. Meanwhile, the deduced amino acid identities of 2010 and 2011 (93.51\% 100\%) were also higher than that of 2011 and 2012 (92.92\% 100\%). All CV-A6 isolates of this study belonged to cluster A1, similar to those found in Shanghai 2011 and 2012, Shenzhen 2011, Thailand 2012, Israel 2012 and 2013, Japan 2011 and France 2010. Our isolates were not similar to those of Chongqing 2011, Henan 2010-2011 and Shandong 2010, which were found by colleagues in Shandong province from 2009-2011 [10], neither to the isolates in Yunnan 2004 nor Yunnan 2010 which fell into cluster B in our analysis (Figure 4).

This epidemiological investigation and molecular phylogenetic analysis indicate that the HFMD epidemic of Guangzhou, is becoming more severe and dynamic in terms of the number and types of causative EVs. In 2011, CV-A6 cases appeared primarily in the summer (June-September). However, the CV-A6 outbreakperiods were significantly different in both 2010 and 2012 and were focused in autumn and winter, with a large peak in the winter of 2012. Since 2008, CV-A6 has caused outbreaks in Spain, France, Finland, Israel, UK, Japan, Singapore, USA and Taiwan [11-16]. From 2009, numerous non-linked reports of infections caused by CV-A2, CV-A4, CV-A5, CV-A6, CV-A9, CV-A10 CV$\mathrm{B} 3$ and $\mathrm{CV}-\mathrm{B} 5$ have been released in Shandong, Henan, Chongqing, Changchun and Qingdao [17-22]. However, to our knowledge, this is the first time that $\mathrm{CV}-\mathrm{A} 6$ was found emerged dramatically as a predominant causative pathogen of HFMD in a metropolis of China. And this may suggest that other EVs, like CV-A6, could become

Table 1 The demographic of patients with different enteroviruses infection from 2010 to 2012

\begin{tabular}{|c|c|c|c|c|c|c|c|c|c|c|c|c|c|c|c|c|c|c|c|c|c|c|}
\hline \multicolumn{3}{|c|}{ Virus } & \multicolumn{4}{|c|}{ EV71 } & \multicolumn{4}{|c|}{ CV-A16 } & \multicolumn{4}{|c|}{ CV-A6 } & \multicolumn{4}{|c|}{$\begin{array}{c}\text { EV71 and CV-A16 } \\
\text { co-infection }\end{array}$} & \multicolumn{4}{|c|}{ Untyped EV } \\
\hline & & V-P & $\mathbf{P}$ & $\begin{array}{c}\text { Cons } \\
\text { ratio (\%) }\end{array}$ & $M$ & $\mathbf{F}$ & $\mathbf{P}$ & $\begin{array}{l}\text { Cons } \\
\text { ratio (\%) }\end{array}$ & $M$ & $\mathbf{F}$ & $\mathbf{P}$ & $\begin{array}{c}\text { Cons } \\
\text { ratio (\%) }\end{array}$ & $M$ & $\mathbf{F}$ & $\mathbf{P}$ & $\begin{array}{c}\text { Cons } \\
\text { ratio (\%) }\end{array}$ & $\mathbf{M}$ & $\mathbf{F}$ & $\mathbf{P}$ & $\begin{array}{c}\text { Cons } \\
\text { ratio (\%) }\end{array}$ & $M$ & $\mathbf{F}$ \\
\hline \multirow{7}{*}{$\begin{array}{l}\text { Age } \\
\text { year }\end{array}$} & $0-$ & 219 & 69 & 5.39 & 43 & 26 & 46 & 4.24 & 33 & 13 & 39 & 7.47 & 28 & 11 & 7 & 8.54 & 5 & 2 & 58 & 10.07 & 34 & 24 \\
\hline & $1-$ & 718 & 264 & 20.61 & 176 & 88 & 150 & 13.81 & 95 & 55 & 173 & 33.14 & 103 & 70 & 17 & 20.73 & 9 & 8 & 114 & 19.79 & 75 & 39 \\
\hline & $2-$ & 714 & 270 & 21.08 & 173 & 97 & 208 & 19.15 & 123 & 85 & 115 & 22.03 & 70 & 45 & 19 & 23.17 & 13 & 6 & 102 & 17.71 & 59 & 43 \\
\hline & 3- & 1063 & 376 & 29.35 & 245 & 131 & 376 & 34.62 & 229 & 147 & 117 & 22.41 & 74 & 43 & 27 & 32.93 & 15 & 12 & 167 & 28.99 & 101 & 66 \\
\hline & 4- & 504 & 177 & 13.82 & 113 & 64 & 192 & 17.68 & 127 & 65 & 48 & 9.20 & 33 & 15 & 9 & 10.98 & 7 & 2 & 78 & 13.54 & 41 & 37 \\
\hline & 5- & 163 & 64 & 5.00 & 37 & 27 & 61 & 5.62 & 40 & 21 & 13 & 2.49 & 11 & 2 & 1 & 1.22 & 0 & 1 & 24 & 4.17 & 15 & 9 \\
\hline & $\geq 6$ & 166 & 61 & 4.76 & 33 & 28 & 53 & 4.88 & 30 & 23 & 17 & 3.26 & 11 & 6 & 2 & 2.44 & 0 & 2 & 33 & 5.73 & 23 & 10 \\
\hline Total & & 3547 & 1281 & 36.12 & 820 & 461 & 1086 & 30.62 & 677 & 409 & 522 & 14.72 & 330 & 192 & 82 & 2.31 & 49 & 33 & 576 & 16.24 & 348 & 228 \\
\hline \multicolumn{3}{|c|}{ Ratio (M/F) } & & 1.78 & & & & 1.66 & & & & 1.72 & & & & 1.48 & & & & 1.53 & & \\
\hline
\end{tabular}



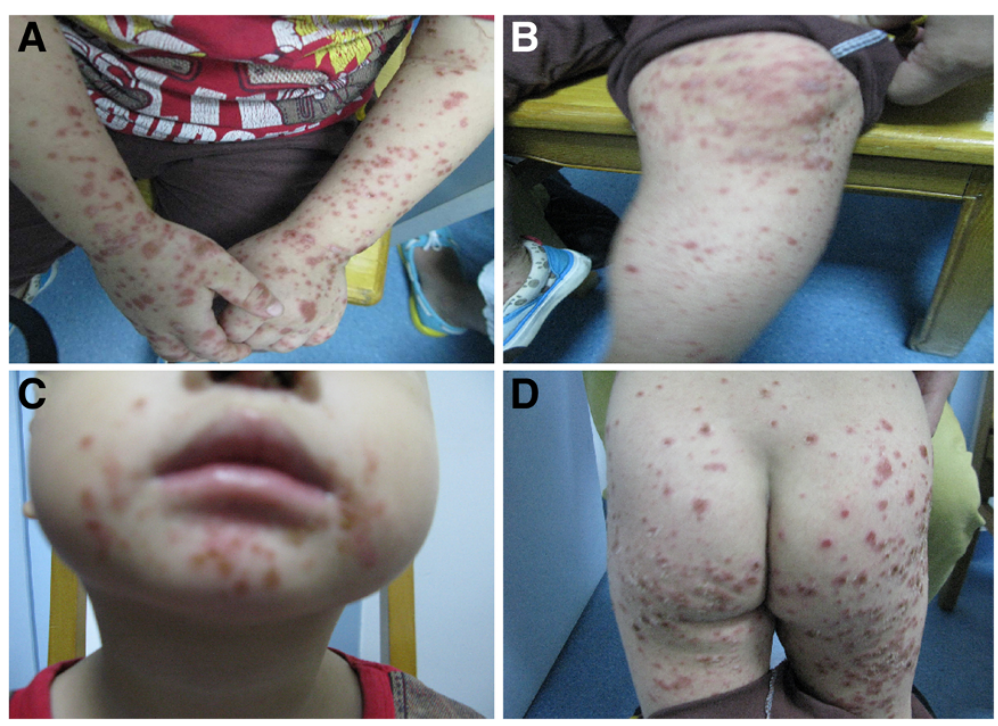

Figure 3 A 2-year-8-month-old boy experienced prominent skin eruption and vesicles with CV-A6 infection in Guangzhou, $2010-2012$. (A) Eruptions on his hand; (B) Eruptions on his foot(especially on his knees); (C) Eruptions around his mouth; (D) Eruption and vesicles on his buttocks.

dominant in the future through introduction to the local population and adaption to the local environment.

Additionally, CV-A6 attack rates were highest in one to two year olds (33.14\%), younger than EV71 and CV-A16 cases which had peak attack-rates in three to four yearolds $(29.35 \%$ and $34.62 \%$, respectively). This CV-A6associated younger cohort poses a risk because younger children have low-resistance and auto-immunity and may present with more complex symptoms. This stresses the importance of maintained surveillance of HFMD infection and education on the signs and symptoms of HFMD in younger children.

We found no phylogenetic explanation for the increase in the number of CV-A6 cases in 2011 and 2012. However we hypothesize that the lack of immunity to this serotype in Guangzhou population contributed to the increased caseload. Additionally, Guangzhou has a sub-tropical climate meaning that autumn and winter are relatively mild. This likely allows the persistent transmission of some EV serotypes, such as CV-A6 throughout the year.

The 8 VP1 sequences separated by the severity of symptoms infected with $\mathrm{CV}$-A6 virus were also included in the Cluster A1 with high homology $(89.25 \%$ 100\%) and were mixed throughout the phylogenetic tree. This indicated that differences in the VP1 region cannot account for differences in severity of disease. Although all CV-A6 isolates of this study were classified into cluster A1, the alignment of 2010-2011 isolates showed a higher nucleic acid and amino acid sequence homology than that of 2012. This could suggest a slight evolutionary shift from 2010-2011 to 2012 .

A retrospective analysis of the HFMD associated symptoms showed that although there were some severe cases, a majority of patients had a typical presentation with symptoms including fever, upper respiratory tract symptoms, maculopapular rash and vesicular exanthema covering the hands, feet and mouth. Although no deaths associated with CV-A6 infections was found, there were still $8(8 / 720,1.11 \%)$ patients who were identified with $\mathrm{CV}-\mathrm{A} 6$ positive, non-bacterial meningitis. This suggests that CV-A6 not only causes common HFMD but can also severely affect the central nervous system. Different from HFMD caused by EV71 or CV-A16, the patients infected by CV-A6 had intraoral lesions and maculopapular on knees obviously in our study.

The timing and presentation of CV-A6 outbreaks have varied in different geographical regions, suggesting some adaptability of the virus. In the Boston HFMD outbreak caused by CV-A6 in the winter of 2012, perioral papules and perirectal eruption exhibited as the characteristic feature in patients [13]. But perirectal eruption was not observed obviously in Finland series CVA6 outbreaks in 2008 and Taiwan CVA6 outbreak in 2010[13,23]. In our study, perirectal eruption was not found visibly.

Similar to Taiwan surveillance from 2004-2009, during which only 3 (2.4\%) of the 141 inpatients with CV-6 infection had central nervous system involvement [24], only $8(8 / 720,1.11 \%)$ of the 720 CV-A6 infectors had meningitis and all recovered uneventfully in our present study. However, an unusually severe outbreak in Nevada, US occurred from November, 2011 to February, 2012 and led to a 19\% hospitalization rate [14]. Cases from the 2010 outbreaks in Spain and Finland presented with onychomadesis $[11,23,25]$, and outbreaks in France (2010) and Japan (2012) CV-A6 cases were also associated with herpangina and onychomadesis [12,13]. But unless specified, 
Figure 4 Phylogenetic analysis of 72 Guangzhou CV-A6 isolates from 2010-2012 (@ 2010 isolates $\bullet 2011$ isolates $\Delta 2012$ isolates $\circ 2011$ severe cases $\Delta 2012$ severe cases) and 38 reference isolates from other Chinese and international locations based on partial VP1 nucleotide sequences. The dendrogram was generated by the neighbor-joining method (bootstrap analysis with 1,000 pseudo replicate data sets) by Mega 5.0. Genotypes are shown to the right of the tress and bootstrap values are shown at each major node. The scale at the bottom indicates a measurement of relative phylogenetic distance.

onychomadesis were often missed because it occurred 1-2 months after infection. These diversities of HFMD presentation demonstrate the importance of symptom monitoring and the physicians should be aware of the emerging pathogens.

An EV71 vaccine is now in stage 3 clinical trials and has proven safe and efficacious for EV71 prevention. However, there is no evidence that it will provide immunity to other EVs such as CV-A16 and CV-A6 [26]. Our research shows that there are many other non-EV71 HFMD-causing EVs that should not be disregarded. Infections caused by more recently detected serotypes such as CV-A6 are not only on the rise but can be associated with severe symptoms. Therefore, even if the EV71 vaccine is highly effective, the number and severity of HFMD cases may not decrease significantly. It is absolutely necessary that future vaccines should target $\mathrm{CV}-\mathrm{A} 6$, the potential major causative pathogen of HFMD. The molecular epidemiology of CV-A6 should also be enhanced as it is highly likely that this virus will continue to contribute significantly to the HFMD case load. Genetic information from various geographical regions will help determine links to severity and pathogenecity as well as evidence for genetic recombination events which could lead to further outbreaks. Improved surveillance of this emerging virus is therefore warranted.

\section{Methods}

\section{Sample collection}

Feces, stool, throat swabs and cerebrospinal fluid samples were collected from HFMD cases presenting at Guangzhou from 5 surveillance hospitals (Guangdong Women and Children Hospital, Guangzhou Yuexiu District Children Hospital, Zengcheng People's Hospital, Guangzhou Huado Distrit People's Hospital, and Huangpu Branch of the First Affiliated Hospital, Sun Yat-sen University) and 12 districts CDCs in Guangzhou. Samples were stored at $-20^{\circ} \mathrm{C}$ and tested at the district level center for disease control and prevention in Guangzhou. From March $1^{\text {st }}$, 2010 to October $30^{\text {th }}, 2012,5482$ samples were collected. Among the specimens, 5 cerebrospinal fluid specimens were collected from fatal cases, 31 specimens were available from severe cases, including throat swabs and stool, 5444 samples were from mild 
outpatients, including feces, stool and throat swabs. All patients (or the guardians of the children patients) gave oral informed consent.

\section{Pretreatment of the samples and extraction of nucleic acid} Feces $(1.5-2 \mathrm{~g})$ and stool samples were dissolved in $2 \mathrm{ml}$ physiological saline $(75 \% \mathrm{NaCl})$ and vortexed for $10 \mathrm{~min}$, followed by centrifugation at 3,800 rcf/min for $5 \mathrm{~min}$. The supernatant was collected and used for RNA extraction. Throat and anal swabs were vortexed in $2 \mathrm{ml}$ physiological saline, centrifuged and the supernatant was used to extract RNA. RNA was extracted from $140 \mu \mathrm{L}$ of pretreated sample using the QIAamp Viral RNA Mini Kit (Qiagen, Hilden, Germany) and eluted in $50 \mu \mathrm{L}$ elution buffer. Throat swab and cerebrospinal fluid specimens were not pre-treated prior to extraction.

\section{CV-A6 detection and genotyping}

The collected samples were amplified using the pan EV fluorescent kit (Guangzhou Huayin medical technology Inc.) for enterovirus detection. A positive sample was defined as any sample with a cycle threshold (Ct) value $\leq 35$. Positive samples were further sub-typed using an EV71/ CV-A16 RNA fluorescent PCR combo-test kit and a CVA6 fluorescent PCR kit (Guangzhou Huayin medical technology Inc.). All tests were performed with the 7500 Fast Real-Time PCR system (Applied Biosystems, USA).

For genotyping CV-A6 isolates, the same RNA extracts were used and RT-snPCR was performed on the partial 5 'region of the VP1 capsid protein, as described by Nix [27] with minor modifications. The first cycle of amplification was performed using the SuperScript ${ }^{\circ}$ One-step RT-PCR Kit (Invitrogen, USA) and 10 pmol of each reverse transcription primer (AN32, AN33, AN34 and AN35) and PCR primers $(222,224), 12.5 \mu \mathrm{l} 2 x \mathrm{PCR}$ reaction buffer, $1 \mu \mathrm{l}$ SuperScript $^{\circ}$ RT/Platinum Taq buffer, $2.5 \mu \mathrm{l}$ template and $\mathrm{ddH}_{2} \mathrm{O}$ to $25 \mu \mathrm{l}$. Reaction conditions were as follows: incubation at $50^{\circ} \mathrm{C}$ for $30 \mathrm{~min}$; denaturation at $94^{\circ} \mathrm{C}$ for $2 \mathrm{~min} ; 30$ cycles of denaturation at $94^{\circ} \mathrm{C}$ for $30 \mathrm{~s}$, annealing at $42^{\circ} \mathrm{C}$ for $30 \mathrm{~s}$, and extension at $60^{\circ} \mathrm{C}$ for $45 \mathrm{~s} ; 10$ cycles of denaturation at $94^{\circ} \mathrm{C}$ for $30 \mathrm{~s}$, annealing at $50^{\circ} \mathrm{C}$ for $30 \mathrm{~s}$, and extension at $68^{\circ} \mathrm{C}$ for $45 \mathrm{~s}$; final extension at $72^{\circ} \mathrm{C}$ for $10 \mathrm{~min}$.

The second cycle of amplification was performed with the PrimeScript One-Step RT-PCR kit (Takara, Japan), $1 \mu \mathrm{l}$ of the RT-PCR product, $0.8 \mu \mathrm{l}$ of the primer pair AN88, AN89 $(20 \mu \mathrm{M}), 25 \mu \mathrm{l}$ of a $2 x P C R$ buffer, and $\mathrm{ddH}_{2} \mathrm{O}$ up to $50 \mu \mathrm{l}$. Reaction conditions were as follows: 40 cycles of denaturation at $98^{\circ} \mathrm{C}$ for $10 \mathrm{~s}$, annealing at $60^{\circ} \mathrm{C}$ for $20 \mathrm{~s}$, and extension at $72^{\circ} \mathrm{C}$ for $35 \mathrm{~s}$; final extension at $72^{\circ} \mathrm{C}$ for $7 \mathrm{~min}$. After purification and collection, the correctly sized PCR products were purified with QIAquick PCR Purification Kit (Qiagen, Hilden, Germany). The amplicons were sequenced with primers
AN233 and AN232 by using an ABI 3130 Genetic Analyzer (Applied Biosystems, USA). Sequences were confirmed using BLAST in NCBI.

\section{Statistical analysis}

Descriptive statistics were performed, and a database was developed for the storage and analysis of study data. The mobidity and constituent ratio were calculated and analyzed by SPSS 13.0 and Microsoft Excel 2007. The statistical differences between proportions were tested by chi-squared test or non-parametric test. A P-value $<0.05$ was regarded as statistically significant.

\section{Analysis of pathogen evolution}

Representative isolates were selected for VP1 nucleic acid sequencing, following the method described above. Sequence data for each isolate was formatted and compiled into contiguous segments using Editseq and Seqman programs (DNASTAR, Mdison, WI). Each virus was analyzed for molecular evolution using Cluster W ((Mega5.0) and a phylogenetic tree was produced using the neighbor joining (Mega5.0) method as described by Oberste et al. Seventy-two CV-A6 VP1 sequences from the present study and $38 \mathrm{VP1}$ sequences from $\mathrm{CV}-\mathrm{A} 6$ isolates available in the GenBank database were used and displayed as a dendrogram containing 110 isolates. The robustness of the analysis was confirmed by bootstrap analysis with 1,000 pseudo replicates. The sequences of EV71 strain $\mathrm{BrCr}$ (U22521) was used as outgroup in the phylogenetic analysis.

Ethics statement: Data was collected as part of government mandated health surveillance and analyzed anonymously so ethical approval was not needed.

\section{Additional file}

Additional file 1: Table S2. Information of 72 representative CV-A6 isolates.

\section{Competing interests}

The authors declare that they have no competing interests.

\section{Author's information}

Dr. Biao Di is a researcher who works in the Virology and Immunology laboratory of the Center for Disease Control and Prevention. His research interests focus on the molecular epidemiology of human enterovirus.

\section{Authors' contributions}

DB and ZY carried out the molecular genetic studies and epidemiology analysis, participated in the sequence alignment and drafted the manuscript. $\mathrm{XH}$ and LX carried out the sample collection, Real-time PCR and virus isolation. CC participated in epidemiology analysis. DP participated in the clinic symptoms record. HP participated in the sequence alignment. WD participated in the design of the study and performed the statistical analysis. GJ participated in the virus isolation. $\mathrm{LL}$ and $\mathrm{BZ}$ participated in sample collection. YZ helped to draft the manuscript. WM took charge of the study design and conceived of it, and helped to draft the manuscript. All authors read and approved the final manuscript. 


\section{Acknowledgements}

The study was supported by the grants from the Major National Science and Technology Project (2012ZX10004-213-005), Guangdong Science and Technology Department program (2012B040304002), Science and Technology Program of Guangzhou Health Department (20131A011110), Guangzhou Science and Technology Department Program (2012Y2-00020), Science and Technology Program of Guangzhou Health Department (20131A011117), Science and Technology Program of Guangzhou Health Department (20131A010022), Science and Technology Program of Guangzhou Health Department (201102A212006).

Received: 19 March 2014 Accepted: 8 August 2014

Published: 1 September 2014

\section{References}

1. Robinson CR, Doane FW, Rhodes AJ: Report of an outbreak of febrile illness with pharyngeal lesions and exanthema: Toronto, summer 1957- isolation of group A Coxsackie virus. Can Med Assoc J 1958, 79:615-621.

2. Kennett ML, Birch CJ, Lewis FA, Yung AP, Locamini SA, Gust ID: Enterovirus type 71 infection in Melbourne. Bull World Health Organ 1974, 51:609-615.

3. Eggertson L: Infectious disease experts monitor outbreaks of enterovirus 71 in Asia. CMA J 2012, 184:E781-E782.

4. Zhu J, Luo Z, Wang J, Xu Z, Chen H, Fan D, Gao N, Ping G, Zhou Z, Zhang Y, An J: Phylogenetic analysis of enterovirus 71 circulating in Beijing, China from 2007 to 2009. PLoS One 2013, 8:e56318.

5. Sun LM, Zheng HY, Zheng HZ, Xue G, He JF, Cuan DW, Kang ML, Liu Z, Ke CW, Li JS, Liu L, Guo RN, Hiromu Y, Lin JY: An enterovirus 71 epidemic in Guangdong Province of China, 2008: epidemiological, clinical, and virogenic manifestations. Jpn J Infect Dis 2011, 64:13-18.

6. Zhang Y, Zhu Z, Yang W, Ren J, Tan X, Wang Y, Mao N, Xu S, Zhu S, Cui A, Zhang $Y$, Yan D, Li Q, Dong X, Zhang J, Zhao Y, Wan J, Feng Z, Sun J, Wang S, Li D, Xu W: An emerging recombinant human enterovirus 71 responsible for the 2008 outbreak of hand foot and mouth disease in Fuyang city of China. Virol J 2010, 7:94

7. Wang Y, Feng Z, Yang Y, Self S, Gao Y, Longini IM, Wakefield J, Zhang J, Wang L, Chen X, Yao L, Stanaway JD, Wang Z, Yang W: Hand, foot, and mouth disease in China: patterns of spread and transmissibility during 2008-2009. Epidemiology 2011, 22:781-792.

8. Li L, He Y, Yang H, Zhu J, Xu X, Dong J, Zhu YF, Jin Q: Genetic characteristics of human enterovirus 71 and coxsackievirus A16 circulating from 1999 to 2004 in Shenzhen, People's Republic of China. J Clin Microbiol 2005, 43:3835-3839.

9. Liang HY, Kang Y, Tao X, Li MX, Luo L: [Dynamic analysis of the epidemiological characteristics of hand-foot-mouth disease during 2008-2011, Guangzhou]. J Tropi Medici 2011, 11(12):1410-1413. Chinese.

10. Lu QB, Zhang XA, Wo Y, Xu HM, Li XJ, Wang XJ, Ding SJ, Chen XD, He C: Circulation of Coxsackievirus $A 10$ and $A 6$ in hand-foot-mouth disease in China, 2009-2011. PLoS One 2012, 7:p.e52073.

11. Davia JL, Bel PH, Ninet VZ, Bracho MA, González-Candelas F, Salaza A, Gobernado M, Bosch IF: Onychomadesis outbreak in Valencia, Spain associated with hand, foot, and mouth disease caused by enteroviruses. Pediatr Dermatol 2011, 28:1-5.

12. Mirand A, Henquell C, Archimbaud C, Ughetto S, Antona D, Bailly JL, Peigue-Lafeuille $\mathrm{H}$ : Outbreak of hand, foot and mouth disease/herpangina associated with coxsackievirus A6 and A10 infections in 2010, France: a large citywide, prospective observational study. Clin Microbiol Infect 2012, 18:E110-E118.

13. Flett K, Youngster I, Huang J, McAdam A, Sandora TJ, Rennick M, Smole S, Rogers SL, Nix WA, Oberste MS, Gellis S, Ahmed AA: Hand, foot, and mouth disease caused by coxsackievirus A6. Emerg Infect Dis 2012, 18:1702-1704.

14. Centers for Disease Control and Prevention Notes from the field: Severe hand, foot, and mouth disease associated with coxsackievirus A6 Alabama, Connecticut, California, and Nevada, November 2011-February 2012. Morb Mortal Wkly Rep 2012, 61:213-214.

15. Ben-Chetrit E, Wiener-Well Y, Shulman LM, Cohen MJ, Elinav H, Sofer D, Feldman I, Marva E, Wolf DG: Coxsackievirus A6-related hand foot and mouth disease: skin manifestations in a cluster of adult patients. J Clin Virol 2014, 59:201-203.
16. Leitch EC, Harvala H, Robertson I, Ubillos I, Templeton K, Simmonds P: Direct identification of human enterovirus serotypes in cerebrospinal fluid by amplification and sequencing of the VP1 region. J Clin Virol 2009, 44:119-124.

17. Hu YF, Yang F, Du J, Zhang T, Wu ZQ, Xue Y, Jin Q: Complete genome analysis of coxsackievirus $\mathrm{A} 2, \mathrm{~A} 4, \mathrm{~A}$, and $\mathrm{A} 10$ isolates isolated from hand, foot, and mouth disease patients in China revealing frequent recombination of human enterovirus A. J Clin Microbiol 2011, 49:2426-2434.

18. Lu QB, Zhang XA, Wo Y, Xu HM, Li XJ, Wang XJ, Ding SJ, Chen XD, He C, Liu LJ, Li H, Yang H, Li TY, Liu W, Cao WC: Circulation of Coxsackievirus A10 and A6 in hand-foot-mouth disease in China, 2009-2011. PLoS One 2012, 7:e52073.

19. Han JF, Jiang T, Fan XL, Yang LM, Yu M, Cao RY, Wang JZ, Qin ED, Qin CF: Recombinationof HumanCoxsackievirus B5in Hand, Foot,and Mouth DiseasePatients, China. Emerg Infect Dis 2012, 18:351-353.

20. Huang YC, Chu YH, Yen TY, Huang WC, Huang LM, Chen AL, Wang HY, Chang LY: Clinical features and phylogenetic analysis of Coxsackievirus A9 in northern Taiwan in 2011. BMC Infect Dis 2013, 13:33.

21. Tao Z, Song Y, Li Y, Liu Y, Jiang P, Lin X, Liu G, Song L, Wang H, Xu A: Coxsackievirus B3, Shandong province, China, 1990-2010. Emerg Infect Dis 2012, 18:1865-1867.

22. Chen L, Mou X, Zhang Q, Li Y, Lin F, Yuan L, Tang Y, Xiang C: Detection of human enterovirus 71 and coxsackievirus $A 16$ in children with hand, foot and mouth disease in China. Mol Med Rep 2012, 5:1001-1004.

23. Österback R, Vuorinen T, Linna M, Susi P, Hyypiä T, Waris M: Coxsackievirus A6 and hand, foot, and mouth disease, Finland. Emerg Infect Dis 2009, 15:1485-1488.

24. Lo SH, Huang YC, Huang CG, Tsao KC, Li WC, Hsieh YC, Chiu CH, Lin TY: Clinical and epidemiologic features of Coxsackievirus A6 infection in children in northern Taiwan between 2004 and 2009. J Microbiol Immunol Infect 2011, 44:252-257.

25. Blomqvista S, Klemola P, Kaijalainen S, Paananen A, Simonen ML, Vuorinen T, Roivainena M: Co-circulation of coxsackieviruses $\mathrm{A} 6$ and $\mathrm{A} 10$ in hand, foot and mouth disease outbreak in Finland. $J$ Clin Virol 2010, 48:49-84.

26. Zhu FC, Meng FY, Li JX, Li XL, Mao QY, Tao H, Zhang YT, Yao X, Chu K, Chen QH, Hu YM, Wu X, Liu P, Zhu LY, Gao F, Jin H, Chen YJ, Dong YY, Liang YC, Shi NM, Ge HM, Liu L, Chen SG, Ai X, Zhang ZY, Ji YG, Luo FJ, Chen XQ, Zhang Y, Zhu LW, Liang ZL, Shen XL: Efficacy, safety, and immunology of an inactivated alum-adjuvant enterovirus 71 vaccine in children in China: a multicentre, randomised, double-blind, placebo-controlled, phase 3 trial. Lancet 2013, 381:2024-2032.

27. Nix WA, Oberste MS, Pallansch MA: Sensitive, seminested PCR amplification of VP1 sequences for direct identification of all enterovirus serotypes from original clinical specimens. J Clin Microbiol 2006, 44(8):2698-2704.

doi:10.1186/1743-422X-11-157

Cite this article as: Di et al:: Circulation of Coxsackievirus A6 in hand-footmouth disease in Guangzhou, 2010-2012. Virology Journal 2014 11:157.

\section{Submit your next manuscript to BioMed Central and take full advantage of:}

- Convenient online submission

- Thorough peer review

- No space constraints or color figure charges

- Immediate publication on acceptance

- Inclusion in PubMed, CAS, Scopus and Google Scholar

- Research which is freely available for redistribution 